\title{
Identified micro-organisms in hospitalized community-acquired pneumonia patients living near goat and poultry farms
}

Inge Roof ${ }^{1 *} \mathbb{D}$, Arianne B. van Gageldonk-Lafeber ${ }^{1}$, Tizza P. Zomer², Yolande M. Vermeeren ${ }^{3}$, Peter C. Wever ${ }^{4}$ and Wim van der Hoek ${ }^{1}$

\begin{abstract}
Background: In the Netherlands, an increased risk of community-acquired pneumonia (CAP) has been reported for adults living near goat and poultry farms. Previous results of respiratory microbiome studies in hospitalized CAP patients near poultry farms suggested a higher relative abundance of Streptococcus pneumoniae. This retrospective study, using routine laboratory data from hospitalized CAP patients, aims to explore possible aetiologic micro-organisms of CAP in relation to livestock exposure.

Methods: Patient characteristics and PCR and urinary antigen test results were retrieved retrospectively from electronic medical records of CAP patients admitted to the Jeroen Bosch Hospital or Gelre Hospital in the Netherlands during 2016-2017. Distances between the patients' home address and the nearest poultry and goat farm were calculated. Differences in laboratory test results between CAP patients with and without goat or poultry farms within $2 \mathrm{~km}$ of their home address were analyzed using Fisher's exact test.
\end{abstract}

Results: In total, 2230 CAP episodes with diagnostic results were included. In only $25 \%$ of the CAP episodes, a microorganism was detected. A positive urinary antigen test for S. pneumoniae was found more often in patients living within two kilometers of goat (15.2\% vs. $11.3 \%$ ) and poultry farms (14.4\% vs. $11.3 \%)$, however these differences were not statistically significant ( $p=0.1047$ and $p=0.1376)$.

Conclusion: Our retrospective analysis did not show statistically significant differences in the identified microorganisms in hospitalized CAP patients related to livestock farming. The study was hampered by limited statistical power and limited laboratory results. Therefore, the potential increased CAP risk around goat and poultry farms will be further explored in a prospective study among CAP patients in primary care.

Keywords: Community-acquired pneumonia, Etiology, Goat farms, Poultry farms, Livestock

\section{Introduction}

In the Netherlands, large numbers of livestock animals are kept in close proximity to human residential areas. This gave rise to concerns among local residents and public health professionals. Previous large epidemiological

\footnotetext{
*Correspondence: inge.roof@rivm.n

${ }^{1}$ Centre for Infectious Disease Control, National Institute for Public Health and the Environment (RIVM), Bilthoven, The Netherlands

Full list of author information is available at the end of the article
}

studies in the Netherlands showed an increased risk of community-acquired pneumonia (CAP) among adults living within a $1-2 \mathrm{~km}$ range of goat and poultry farms. [1-5] Based on data from electronic medical records, the association with general practitioner (GP) diagnosed CAP has been repeatedly present from 2009 to 2016 for goat farms. Although the association with poultry farms has also been found in the United States [6], in more recent studies in the Netherlands the associations with 
poultry farms were not significant or positive in only a part of the analyses. [2, 7] During 2014-2016, an estimated 6.0 to $7.8 \%$ of CAP cases in a study population in the south of the Netherlands were attributable to living in the vicinity of goat farms. [5] The association between CAP and goat farms led to a temporary stop on issuing building permits for new and existing goat farms in most Dutch provinces. [8]

CAP is mostly a clinical diagnosis with only limited information on the aetiologic micro-organisms. It has been proposed that exposure to particulate matter (PM) and its components (e.g. micro-organisms and endotoxins) may increase the susceptibility to CAP. [9-11] Previous results suggested a shift in the respiratory microbiome composition in hospitalized pneumonia patients near poultry farms, with a higher relative abundance of Streptococcus pneumoniae. [3] While most CAP patients in the Netherlands are managed by the GP, yearly, around 40,000-50,000 pneumonia patients in the Netherlands require hospitalization. Even in hospitalized CAP patients, the causative organism is not specified in $85 \%$ of cases when routine diagnostics are applied [12]. Despite this limitation, in preparation for a large prospective aetiological study, we still decided to analyze the laboratory management systems of two hospitals in livestock dense areas for relevant microbiological test data, especially for S. pneumoniae, to explore the identified micro-organisms in pneumonia patients in relation to livestock exposure.

\section{Methods}

\section{Study design and data collection}

We used laboratory data from CAP patients admitted to Jeroen Bosch Hospital (JBH) or Gelre Hospital (Gelre) in the Netherlands during the period Jan 1, 2016 - Dec 31, 2017. These hospitals were chosen based on their location within livestock dense areas. Within the catchment area of JBH live 360.000 people. The catchment area of Gelre includes approximately 280.000 inhabitants. Patients were selected based on financial reimbursement codes (DBC, Dutch acronym: Diagnose Behandel Code) specific for CAP. Reimbursement codes for CAP in children (age below 18 years) were excluded. No ethical approval was needed as patient records were used retrospectively.The variables age, gender, postal code and date of sample collection were retrieved from the electronic patient record and combined with laboratory test results. For both hospitals, results were available from PCR on influenza virus $\mathrm{A}$ and $\mathrm{B}$, and from urinary antigen tests for Legionella pneumophila serogroup 1 and S. pneumoniae. Additionally, data from Gelre hospital included test results from a PCR panel on human metapneumovirus, adenovirus, Chlamydia pneumoniae, rhinovirus, coronavirus, Chlamydia psittaci and Mycoplasma pneumoniae. Test results from the same patient with an interval of more than 1 month were considered as a new CAP episode. For each episode the variable 'diagnosis' was added and was considered positive when at least one micro-organism, irrespective of the type, was reported in any of the laboratory test results.

\section{Livestock farm exposure}

We obtained the goat and poultry farm locations from the Netherlands Enterprise Agency, which collects livestock farm data on behalf of the Ministry of Agriculture, Nature and Food Quality. The location and characteristics of the goat and poultry farms were available for April 2016 and April 2017. The year of livestock farming data used, corresponded with the year of hospital admission. Only livestock farms with a minimum number of 50 goats and 250 poultry birds were included. The postal codes of patients' residential addresses were geocoded and distances between these coordinates and the nearest poultry and goat farm were calculated using ArcGis. A binary variable, indicating the presence of a farm of a specific type within two kilometers of the home address, was created. The cut-off of two kilometer was selected based on the results of previous studies. [2, 5]

\section{Statistical analysis}

Descriptive statistics were performed with categorical variables presented as percentages and continuous variables as median with interquartile range. Differences in categorical and continuous variables were calculated using Fisher's exact test and the Wilcoxon rank-sum test, respectively. All data were analyzed using SAS software version 9.4 (SAS Institute Inc., Cary, NC, USA). A $p$-value of 0.05 was considered statistically significant.

\section{Results}

\section{Characteristics CAP episodes}

For the years 2016-2017, a total of 2230 CAP episodes $(n=1275 \mathrm{JBH}, n=955 \mathrm{Gelre})$ with diagnostic test results for PCR and/or urinary antigen tests were included, representing 1928 unique patients. Of the total number of CAP episodes, $12.4 \%$ (JBH 19.1\%, Gelre 3.6\%) and $16.6 \%$ (JBH 18.2\%, Gelre 14.5\%) occurred in patients living within a two kilometer range of goat farms or poultry farms, respectively (Table 1 ). A similar age distribution was observed between the CAP patients with and without livestock presence. The group living close to poultry farms consisted of a higher percentage of males $(p=0.0113)$. Diagnostic tests were able to detect a micro-organism in around a quarter of the CAP episodes in each livestock exposure group. No associations were 
Table 1 Characteristics of hospitalized pneumonia patients, grouped by livestock farm exposure

\begin{tabular}{|c|c|c|c|c|c|c|}
\hline & $\begin{array}{l}\text { Goat farm } \\
\leq 2 \mathrm{~km} \\
\mathrm{~N}(\%)\end{array}$ & $\begin{array}{l}\text { Goat farm } \\
>2 \mathrm{~km} \\
\mathrm{~N}(\%)\end{array}$ & P-value & $\begin{array}{l}\text { Poultry farm } \leq 2 \mathrm{~km} \\
\mathrm{~N}(\%)\end{array}$ & $\begin{array}{l}\text { Poultry farm }>2 \mathrm{~km} \\
\mathrm{~N}(\%)\end{array}$ & $P$-value \\
\hline N & $277(12.4)$ & 1953 (87.6) & & $370(16.6)$ & 1860 (83.4) & \\
\hline Median age, years [IQR] & $73[18]$ & $72[19]$ & 0.1740 & $72[20]$ & $72[19]$ & 0.9810 \\
\hline Male gender & $162(58.5)$ & $1121(57.4)$ & 0.7458 & $235(65.5)$ & $1048(56.3)$ & 0.0113 \\
\hline Positive diagnosis & $66(23.8)$ & $493(25.2)$ & 0.6569 & $100(27.0)$ & $459(24.7)$ & 0.3579 \\
\hline \multicolumn{7}{|l|}{ Season of admission } \\
\hline Apr-Sep & $108(39.0)$ & 708 (36.3) & 0.3866 & $135(36.5)$ & $681(36.6)$ & 1.0000 \\
\hline Oct-Mar & $169(61.0)$ & $1245(63.7)$ & & 235 (63.5) & 1179 (63.4) & \\
\hline
\end{tabular}

found between season of admission and goat or poultry farm presence (Table 1).

\section{Micro-organisms identified}

Within the laboratory data, PCR test results were available for influenza virus A and B $(n=1109)$ and urinary antigen test results for $L$. pneumophila serogroup 1 $(n=1837)$ and S. pneumoniae $(n=1799)$. Comparing patients exposed and non-exposed to goat or poultry farms within two kilometers of their home address, showed no statistically significant differences with regard to test results for influenza virus $\mathrm{A}$ and $\mathrm{B}$, and $L$. pneumophila serogroup 1 (Table 2). Higher percentages of positive urinary antigen tests for S. pneumoniae were found for patients living close to goat (15.2\% vs. $11.3 \%)$ and poultry farms $(14.4 \%$ vs. $11.3 \%)$, however, these differences were not statistically significant (Table 2, $p=0.1047$ and $p=0.1376$ ). When analyzing CAP episodes from JBH separately, a positive urinary antigen test for S. pneumoniae was significantly associated with poultry farm exposure ( $p=0.0318$, data not shown). Analysis of the PCR panel for CAP episodes from the Gelre Hospital showed no differences in any of the included microorganisms (data not shown).

\section{Discussion}

This retrospective analysis of laboratory tests in hospitalized CAP patients did not show significant differences in the identified micro-organisms between patients with and without goat and poultry farms in the vicinity of their home address.

Based on previous research, in which a shift in the respiratory microbiome with higher abundance of $S$. pneumoniae in hospitalized CAP patients close to poultry farms was observed [3], we hypothesized to find a higher percentage of positive tests for S. pneumoniae in patients exposed to livestock. However, in our study a positive urinary antigen test for $S$. pneumoniae was not significantly associated with poultry or goat farm presence around the patients' home address. An explanation might be that we used results from urinary antigen tests, a relative insensitive test compared to the 16S-rRNA based sequencing to determine S. pneumoniae presence used in the study by Smit et al. [3] Moreover, Smit et al. used a one kilometer distance as cut-off point for poultry farm presence instead of the two kilometers distance we defined. The number of people living within one kilometer of goat or poultry farms in our study was too low for proper statistical analysis. When analyzing the urinary antigen tests for

Table 2 Laboratory results of PCR and urinary antigen tests of pneumonia patients, grouped by livestock farm exposure

\begin{tabular}{|c|c|c|c|c|c|c|c|}
\hline & & $\begin{array}{l}\text { Goat farm } \\
\leq 2 \mathrm{~km} \\
\mathrm{~N}(\%)\end{array}$ & $\begin{array}{l}\text { Goat farm } \\
>2 \mathrm{~km} \\
\mathrm{~N}(\%)\end{array}$ & P-value & $\begin{array}{l}\text { Poultry farm } \leq 2 \mathrm{~km} \\
\mathrm{~N}(\%)\end{array}$ & $\begin{array}{l}\text { Poultry farm > } 2 \mathrm{~km} \\
\mathrm{~N}(\%)\end{array}$ & $P$-value \\
\hline Influenza A PCR & $\begin{array}{l}\text { Pos } \\
\text { Neg }\end{array}$ & $\begin{array}{l}17(17.0) \\
83(83.0)\end{array}$ & $\begin{array}{l}152(15.1) \\
857(84.9)\end{array}$ & 0.5628 & $\begin{array}{l}32(18.0) \\
146(82.0)\end{array}$ & $\begin{array}{l}137(14.7) \\
794(85.3)\end{array}$ & 0.2574 \\
\hline Influenza B PCR & $\begin{array}{l}\text { Pos } \\
\text { Neg }\end{array}$ & $\begin{array}{l}6(5.9) \\
95(94.1)\end{array}$ & $\begin{array}{l}27(2.7) \\
981(97.3)\end{array}$ & 0.1125 & $\begin{array}{l}5(2.8) \\
173(97.2)\end{array}$ & $\begin{array}{l}28(3.0) \\
903(97.0)\end{array}$ & 1.0000 \\
\hline Legionella urinary antigen test ${ }^{*}$ & $\begin{array}{l}\text { Pos } \\
\text { Neg }\end{array}$ & $\begin{array}{l}7(2.9) \\
239(97.1)\end{array}$ & $\begin{array}{l}29(1.8) \\
1562(98.2)\end{array}$ & 0.3175 & $\begin{array}{l}8(2.7) \\
288(97.3)\end{array}$ & $\begin{array}{l}28(1.8) \\
1513(98.2)\end{array}$ & 0.3561 \\
\hline Pneumococcal urinary antigen test ${ }^{\#}$ & $\begin{array}{l}\text { Pos } \\
\text { Neg }\end{array}$ & $\begin{array}{l}36(15.2) \\
201(84.8)\end{array}$ & $\begin{array}{l}177(11.3) \\
1385(88.7)\end{array}$ & 0.1047 & $\begin{array}{l}42(14.4) \\
249(85.6)\end{array}$ & $\begin{array}{l}171(11.3) \\
1337(88.7)\end{array}$ & 0.1376 \\
\hline
\end{tabular}

\footnotetext{
"Legionella pneumophila serogroup 1
}

"Streptococcus pneumoniae 
CAP episodes from JBH only, we did find a statistically higher percentage of positive urinary antigen tests for S. pneumoniae in patients living close to poultry farms (15.6\%) compared to patients living more than two kilometers from poultry farms (10.1\%). Compared to Gelre hospital, urinary antigen tests were more often performed at JBH and a higher percentage of patients from JBH live within two kilometers of a livestock farm.

Prior studies regarding CAP and proximity to livestock farming used electronic medical records from GPs, reflecting mostly outpatient CAP. Our present study was among hospitalized CAP patients, i.e. a more severe patient population. The identified micro-organisms in these hospitalized patients might not entirely reflect the etiology of CAP patients visiting their GP. No patterns with goat or poultry farm exposure were detected for the micro-organisms included in a respiratory PCR panel (e.g. human metapneumovirus, adenovirus, rhinovirus, coronavirus, C. pneumoniae, C. psittaci and M. pneumoniae). Because of differences in diagnostic testing strategies, results from this PCR panel were only available for CAP episodes from Gelre Hospital. Unfortunately, the low prevalence of goat farms around the home addresses of these patients (3.6\%) hampered the analyses of these micro-organisms due to limited statistical power.

In around $75 \%$ of the CAP episodes included in our study, no pathogens were detected. The failure to detect a pathogen has often been described in scientific literature, with estimates ranging from 20 to $45 \%$ of patients. [1317] The high percentage of diagnostic failure reported in this study, might be related to the fact that our data was limited to routine diagnostics performed in these patients. A comprehensive and broad diagnostic package can increase diagnostic yield. However, we did not include test results from serology and bacterial culture, because these results often require an extra interpretation step.

During the large Q-fever epidemic in the Netherlands, from 2007 to 2010, Coxiella burnetii, was clearly an important zoonotic cause of CAP among people living close to Q-fever-affected goat farms. An observational study on CAP etiology in the Netherlands, that coincided with this Q-fever outbreak, showed that $C$. burnetii was the second most common pathogen in that study population. [16] However, in more recent years, after the epidemic, it was unlikely that Q-fever still played a role. $C$. burnetii seropositivity among CAP patients was independent from goat farm exposure and the increased CAP incidence was also found around Q-fever negative farms. $[2,4]$ In our study, very little to no Q-fever diagnostics had been requested in the CAP episodes included from the JBH, the hospital which is located within the former Q-fever epidemic area.
Our study was limited by multiple factors. First, the analysis was hampered by the small number of identified micro-organisms and the low prevalence of livestock exposure around some of the home addresses of patients. Therefore we only analyzed the laboratory results in relation to livestock farm exposure by crude univariate analysis. The small numbers and low prevalence also did not allow for further classification of the livestock exposure variable. We chose to handle a $2 \mathrm{~km}$ distance cut-off based on the results from previous research, but further classification using buffers or regression frameworks, as used in previous studies, was not appropriate. Second, as we did not have additional patient characteristics such as comorbidities, lifestyle factors and medication use, we could not address potential confounding by certain risk factors in our analyses. The age of the CAP patients was similarly distributed between the groups with and without livestock farm proximity. Finally, potential selection bias is also of concern because not every patient was tested for each pathogen. We retrospectively used laboratory data initially performed for diagnostic purposes, meaning that the data is dependent on the prevailing testing strategies in both hospitals. It might be that physicians only test for certain pathogens in the more severe patient group. Still the overall pathogen detection rate of around $25 \%$, as presented in Table 1, was comparable between the CAP patients with and without goat and poultry farm exposure.

This explorative study did not provide information about possible causes of the increased CAP risk around goat and poultry farms. The previous associations are based on diagnostic data from GPs. In the Netherlands, around $80 \%$ of all CAP patients are managed by the GP. The causative pathogen, however, remains unknown in the majority of CAP patients as microbiological testing is not included in the pneumonia guidelines of the Dutch College of General Practitioners. [18, 19] To gather insight in CAP etiology related to livestock farming in a primary care setting, we started a prospective study in CAP patients visiting their GP including extensive microbiological diagnostics by multiplex PCR and respiratory microbiome analyses.

\section{Abbreviations \\ CAP: Community-acquired pneumonia; GP: General practitioner; PM: Particu- late matter; JBH: Jeroen Bosch Hospital; Gelre: Gelre Hospital.}

\section{Acknowledgements}

We would like to thank Ben Bom (National Institute for Public Health and the Environment, Bilthoven) for performing the distance calculations between the patients' home address and livestock farms. Furthermore, we would like to thank Eric Hazenberg (Jeroen Bosch Hospital, 's-Hertogenbosch) for providing the laboratory data. 


\section{Authors' contributions}

IR, ABvG and WvdH designed the study. IR, TZ, YV and PW contributed to data acquisition. IR, ABvG and WvdH were involved in statistical analysis and data interpretation. Writing of the original draft was performed by IR and $A B V G, T Z$, YV, PW and WvDH participated in reviewing and editing the manuscript. All authors read and approved the final manuscript.

\section{Funding}

This study was funded by the Ministry of Health, Welfare and Sport of the Netherlands. The funders had no role in study design, data collection, data analysis, decision to publish or preparation of the manuscript.

\section{Availability of data and materials}

The datasets used and/or analyzed during the current study are available from the corresponding author on reasonable request.

\section{Declarations}

\section{Ethics approval and consent to participate}

No ethical approval was needed as patient records were used retrospectively.

\section{Consent for publication}

Not applicable.

\section{Competing interests}

The authors declare that they have no competing interests.

\section{Author details}

${ }^{1}$ Centre for Infectious Disease Control, National Institute for Public Health and the Environment (RIVM), Bilthoven, The Netherlands. ${ }^{2}$ Department of Medical Microbiology and Infection Prevention, Gelre Hospital, Apeldoorn, the Netherlands. ${ }^{3}$ Department of Internal Medicine, Gelre Hospital, Apeldoorn, the Netherlands. ${ }^{4}$ Department of Medical Microbiology and Infection Control, Jeroen Bosch Hospital, 's-Hertogenbosch, the Netherlands.

Received: 2 July 2021 Accepted: 15 November 2021

Published online: 29 November 2021

\section{References}

1. Smit LA, van der Sman-de Beer F, Opstal-van Winden AW, Hooiveld M, Beekhuizen J, Wouters IM, et al. Q fever and pneumonia in an area with a high livestock density: a large population-based study. PLoS One. 2012;7(6):e38843.

2. Freidl GS, Spruijt IT, Borlee F, Smit LA, van Gageldonk-Lafeber AB, Heederik DJ, et al. Livestock-associated risk factors for pneumonia in an area of intensive animal farming in the Netherlands. PLoS One. 2017;12(3):e0174796.

3. Smit LAM, Boender GJ, de Steenhuijsen Piters WAA, Hagenaars TJ, Huijskens EGW, Rossen JWA, et al. Increased risk of pneumonia in residents living near poultry farms: does the upper respiratory tract microbiota play a role? Pneumonia (Nathan Qld). 2017:9:3.

4. Kalkowska DA, Boender GJ, Smit LAM, Baliatsas C, Yzermans J, Heederik DJJ, et al. Associations between pneumonia and residential distance to livestock farms over a five-year period in a large population-based study. PLoS One. 2018;13(7):e0200813.

5. Post PM, Hogerwerf L, Huss A, Petie R, Boender GJ, Baliatsas C, et al. Risk of pneumonia among residents living near goat and poultry farms during 2014-2016. PLoS One. 2019;14(10):e0223601.

6. Poulsen MN, Pollak J, Sills DL, Casey JA, Nachman KE, Cosgrove SE, et al. High-density poultry operations and community-acquired pneumonia in Pennsylvania. Environmental Epidemiology. 2018;2(2):e013.

7. van Dijk CE, Zock JP, Baliatsas C, Smit LAM, Borlee F, Spreeuwenberg P, et al. Health conditions in rural areas with high livestock density: Analysis of seven consecutive years. Environmental pollution (Barking, Essex: 1987). 2017;222:374-82.

8. ANP. Ook Overijssel zet rem op geitenboerderijnen [Overijssel puts a stop on goat farms as well] Binnenlands Bestuur Sijthoff Media Groep Amsterdam. 2018.
9. Neupane B, Jerrett M, Burnett RT, Marrie T, Arain A, Loeb M. Long-term exposure to ambient air pollution and risk of hospitalization with community-acquired pneumonia in older adults. Am J Respir Crit Care Med. 2010;181(1):47-53.

10. Soukup JM, Becker S. Human alveolar macrophage responses to air pollution particulates are associated with insoluble components of coarse material, including particulate endotoxin. Toxicol Appl Pharmacol. 2001;171(1):20-6

11. Lee A, Kinney $P$, Chillrud S, Jack D. A systematic review of innate Immunomodulatory effects of household air pollution secondary to the burning of biomass fuels. Annals of global health. 2015;81(3):368-74.

12. Benincà $E$, van Boven $M$, Hagenaars $T$, van der Hoek W. Space-time analysis of pneumonia hospitalisations in the Netherlands. PLoS One. 2017;12(7):e0180797.

13. Capelastegui A, España PP, Bilbao A, Gamazo J, Medel F, Salgado J, et al. Etiology of community-acquired pneumonia in a population-based study: link between etiology and patients characteristics, process-of-care, clinical evolution and outcomes. BMC Infect Dis. 2012:12:134.

14. Ewig S, Torres A, Angeles Marcos M, Angrill J, Rañó A, de Roux A, et al. Factors associated with unknown aetiology in patients with communityacquired pneumonia. Eur Respir J. 2002;20(5):1254-62.

15. Templeton KE, Scheltinga SA, van den Eeden WC, Graffelman AW, van den Broek PJ, Claas EC. Improved diagnosis of the etiology of communityacquired pneumonia with real-time polymerase chain reaction. Clin Infect Dis. 2005:41(3):345-51.

16. van Gageldonk-Lafeber AB, Wever PC, van der Lubben IM, de Jager $C P$, Meijer A, de Vries MC, et al. The aetiology of community-acquired pneumonia and implications for patient management. Neth J Med. 2013;71(8):418-25.

17. Huijskens EG, Rossen JW, Kluytmans JA, van der Zanden AG, Koopmans M. Evaluation of yield of currently available diagnostics by sample type to optimize detection of respiratory pathogens in patients with a community-acquired pneumonia. Influenza Other Respir Viruses. 2014;8(2):243-9.

18. Verheij ThJM HR, Prins JM, Salomé PL, Bindels PJ, Ponsioen BP, Sachs APE, et al. NHG-Standaard Acuut hoesten (Eerste herziening). Huisarts Wet. 2011:54(2):68-92.

19. Snijders B, van der Hoek W, Stirbu I, van der Sande MAB, van GageldonkLafeber AB. General practitioners' contribution to the management of community-acquired pneumonia in the Netherlands: a retrospective analysis of primary care, hospital, and national mortality databases with individual data linkage. Prim Care Respir J. 2013;22(4):400-5.

\section{Publisher's Note}

Springer Nature remains neutral with regard to jurisdictional claims in published maps and institutional affiliations.

Ready to submit your research? Choose BMC and benefit from

- fast, convenient online submission

- thorough peer review by experienced researchers in your field

- rapid publication on acceptance

- support for research data, including large and complex data types

- gold Open Access which fosters wider collaboration and increased citations

- maximum visibility for your research: over 100M website views per year

At BMC, research is always in progress.

Learn more biomedcentral.com/submissions 